\title{
EVERSION OF THE UTERUS IN A MARE.
}

By H. G. Rodgers, M.R.C.V.S., Ross, Herefordshire.

ON Friday morning, the 22nd November last, I was called along with Mr Barling, whose assistant I am, to attend a mare reported to have "her womb out." On arrival we found the animal-a valuable cart mare-standing with her uterus everted and hanging down to the level of her hocks. We ascertained that the mare had aborted a seven month's foal some hours previously, and that the womb had immediately thereafter made its appearance. As may be imagined, the organ was greatly engorged; the mare showed much depression; the pulse was 90 per minute, and very feeble.

We began operations by carefully and thoroughly cleansing the surface of the uterus by washing with warm water, at the same time removing every shred of placental membrane. We then attempted to return the womb, and our efforts were successful. To prevent its being again everted, three tape sutures were passed through the labia, and a physic ball and a draught containing chloral hydrate and tincture of opium were administered to the mare. 'A second draught was left with directions that it should be given after an interval of three hours.

On returning the same evening we found that the mare was doing well. The pulse was 70 , and decidedly stronger. The mare took a little mash. A draught containing spirit of nitrous æther and chloral hydrate was administered.

Saturday morning. The condition of the mare was found to be satisfactory. Pulse 50 and stronger; temperature IOI ${ }^{\circ}$. There was a slight amount of discharge from the uterus, and its cavity was therefore syringed with a solution of Jeye's fluid of the strength of I to 40 of water, a sedative draught being at the same time administered.

Saturday evening. The mare's condition was found to be about the same as in the morning; she was taking a little food, and the physic was acting moderately. Pulse 50, temperature IOI $^{\circ}$. The genital passages were syringed with the above antiseptic solution, and febrifuge powders, to be given morning and evening in the drinking water, were left.

Sunday morning. Condition of patient satisfactory. Pulse down to 46 . Increased amount of discharge from the vulva. The syringing was again carried out, and orders were given to have this repeated every four hours.

Monday morning. The mare was found to be suffering from laminitis of the fore feet. The pulse had increased to 90 , temperature $102^{\circ}$, breathing hurried. We had the shoes removed, and the feet put in cold bran poultices. Cold water was constantly poured over the affected feet, and a draught containing nitrous ather, acetate of ammonia, and tincture of aconite was administered. Syringing continued as before.

Monday evening. We were again sent for, as the mare was showing colicky symptoms, and breathing very rapidly. On arrival we found that the disturbance was due solely to the pain in the feet, and, as the bowels were not acting, another physic ball was administered.

During the next three days the mare made steady progress under 2 A 
the same treatment, the syringing being reduced first to thrice and then to once daily. At the end of a week she was gently exercised in a loose box, and the shoes were afterwards put on. On Tuesday, the 3rd December, the mare was found to be quite convalescent.

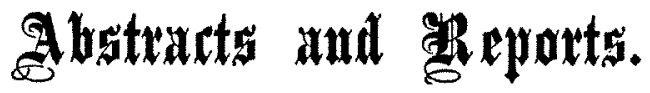

\section{THE EXAMINATION OF FLESH FOR THE TRICHINA SPIRALIS.}

HERTwIG finds that the trichinæ are most frequently present in the pillars of the diaphragm. Out of 150 trichinous pigs examined, the parasites were not found in the pillars in only ten animals, in which the trichinæ were very sparingly present. $\mathrm{He}$ is therefore of opinion that it is better to examine many preparations from the diaphragmatic pillars than a few preparations from each of several groups of muscles. The examination of the intercostal and eye muscles might be omitted. That the method of examining preparations from many groups of muscles affords no certainty of discovery, is proved by the fact that in two years thirty-four pigs were found to be trichinous on re-examination at the Berlin abattoir, and thirty-two of these came from the province of Brandenburg, in which the above method is practised.-Thiermedicinische Rundschau, ist November 1889 .

\section{INFECTION OF A POULTRY-YARD BY A PHTHISICAL MAN.}

DURIEUX reports the following case in the Annales de Medicine Veternaire :In a certain poultry-yard the death rate suddenly became very high. The fowls which were affected became extremely emaciated, squatted motionless in some corner, with the head and neck hidden in the feathers, and the comb decolorised.

The autopsy of some of these birds showed the liver crammed with tubercles of the size of a pin's head; larger tubercles were present in the intestines. Koch's bacilli were found in these tumours, thus proving their tubercular nature.

On inquiry the author learned that a consumptive man who expectorated a great deal had often passed a part of the day in the court-yard of the farm where the fowls went, and that the latter had greedily consumed the sputum expectorated by the patient.-Recueil de Med. Vet., I 5 th December 1889 .

\section{THE TREATMENT OF LARYNGO-PHARYNGITIS IN THE HORSE.}

JELKMANN strongly recommends the intra-laryngeal injection of a solution containing muriate of morphia and hydrocyanic acid in the treatment of acute laryngo-pharyngitis occurring in horses. He has already treated about 200 cases in this way, and finds that hydrocyanic acid in combination with morphia 